\title{
Genetic variation in fatness and fatty acid composition of crossbred cattle ${ }^{1}$
}

\author{
W. S. Pitchford ${ }^{* 2}$, M. P. B. Deland $\dagger$, B. D. Siebert*, A. E. O. Malau-Aduli*3 \\ and C. D. K. Bottema*
}

*Livestock Systems Alliance, University of Adelaide, Roseworthy SA 5371, Australia, and †Struan Research Centre, South Australian Research and Development Institute, Naracoorte SA 5271, Australia

\begin{abstract}
Mature Hereford cows (766) were mated to 97 sires from seven breeds (Jersey, Wagyu, Angus, Hereford, South Devon, Limousin, and Belgian Blue), resulting in 1,215 calves born over 4 yr (1994 to 1997). These cattle comprised Australia's "Southern Crossbreeding Project." Heifers were slaughtered at an average of 16 mo with hot standard carcass weight of $219 \mathrm{~kg}$ and $9 \mathrm{~mm}$ fat over the rump. Steers were slaughtered at an average of 23 mo with carcass weight of $319 \mathrm{~kg}$ and $13 \mathrm{~mm}$ fat over the rump. Meat and fat samples were taken from the carcass on the day after slaughter for subsequent laboratory analysis of i.m. fat content and fatty acid composition. Data were analyzed using uni- and bivariate animal models containing fixed effects of cohort, management group, birth month, and sire breed. March-born calves had fat with a $0.5^{\circ} \mathrm{C}$ lower melting point, $0.6 \%$ higher total monounsaturated fatty acids, and $0.7 \%$ higher fatty acid desaturation index than calves born in April. Steers born in 1997 were the only cohort finished on pasture, and they had much
\end{abstract}

more yellow fat than the other cohorts. Four heavy breed crosses (Angus, South Devon, Limousin, and Belgian Blue) averaged $284 \mathrm{~kg}$ carcass weight, followed by purebred Hereford (268 kg), Wagyu (244 kg) and Jersey $(236 \mathrm{~kg})$. Angus had the greatest fat depth $(14.3 \mathrm{~mm})$, ahead of Hereford and Wagyu (11.9 mm), Jersey (10.7 $\mathrm{mm})$, South Devon and Limousin $(9.9 \mathrm{~mm})$ and Belgian Blue $(8.0 \mathrm{~mm})$. Jersey, Wagyu, and Angus had the most i.m. fat (4.6\%), followed by Hereford and South Devon (3.8\%), and Limousin and Belgian Blue (3.1\%). The highly marbled Jersey and Wagyu had softer fat (6\% lower fat melting point) than the other breeds. Angus were more highly marbled, similar to Jersey and Wagyu, but had harder fat similar to the leaner breeds. Heritabilities for all traits were low to moderate (16 to $36 \%$ ). Genetic correlations between fatty acid composition and carcass traits were not significant, indicating little evidence of antagonisms between traits that would prevent genetic progress in both production and quality.

Key Words: Beef Cattle, Fatty Acids, Genetic Parameters

(C2002 American Society of Animal Science. All rights reserved.

J. Anim. Sci. 2002. 80:2825-2832

\section{Introduction}

Marbling (i.m. fat content) is currently an important determinant of carcass value for markets, such as Aus-

\footnotetext{
${ }^{1}$ The authors thank Geb Mekonnen, Matthew Riemann, and Ben Hebart for assistance with fat extraction and fatty acid analyses. Zbyszek Kruk, David Rutley, Elke Stephens, Tony Weatherly, and Mohammad Edriss assisted with the cattle slaughters and in numerous other ways. Michael Milne and farm staff at Struan assisted with both live and carcass measurements. The initial funding for the Southern Crossbreeding Project was obtained from the South Australian Cattle Compensation Trust Fund and the J.S. Davies Bequest to the University of Adelaide (including salary for Cynthia Bottema). Enoch Malau-Aduli was awarded a scholarship from AusAid. Tony Davis (AW\&PR Davis Pty. Ltd.) funded the feedlot phase of the project, and the Australian Research Council in partnership with Elders Ltd. funded the fat analyses and provided financial assistance for Brian Siebert. We would especially like to thank Nick Crichton from Elders for his foresight that led to joint work and his involvement throughout the project.
}

tralian beef destined for Japan (Baud et al., 1998). Melting point of fat in carcasses determines the hardness or softness of fat, which is important in Japanese markets that prefer soft fat. Other research groups (e.g., Perry et al., 1998) in addition to our own (e.g., Malau-Aduli et al., 1998) have reported significant sire-breed differences in melting point of fat from steers. Fat melting point is determined by the melting point of its fatty acid components. Differences between cattle breeds in fatty acid composition have been reported for Brahman and Hereford (Huerta-Leindenz et al., 1993), Hereford crossbreds

\footnotetext{
${ }^{2}$ Correspondence: (phone: +61 8 83037642; fax: + 618 83037972; E-mail: Wayne.Pitchford@adelaide.edu.au).

${ }^{3}$ Present address: Department of Livestock and Grassland Science, National Research Centre for Western Regions, 60 Yoshinga, Kawai, Oda, Shimane 694-0013, Japan.

Received November 19, 2001.

Accepted July 10, 2002.
} 
(Siebert et al., 1996), and between Limousin and Jersey (Malau-Aduli et al., 1997).

In contrast, the number of published estimates of genetic parameters for fatty acids are scant, and mostly available in pigs (Bout et al., 1991; Cameron and Enser, 1991). Apart from preliminary reports of the current study (Malau-Aduli et al., 1998, 2000), published estimates are not available. Therefore, the objective of this study was to present breed differences and genetic parameters for fat traits in beef using the complete data set of fat traits from the Australian "Southern Crossbreeding Project."

\section{Methods}

\section{Animals and Management}

The "Southern Crossbreeding Project" was conducted at Struan Research Centre, Naracoorte, South Australia, and in various commercial feedlots in southern Australia. The aim of the project was to characterize between- and within-breed genetic variation for production, carcass, and meat quality traits. A description of the project was provided by Rutley et al. (1995), and a preliminary analysis of a subset of the data was reported by Malau-Aduli et al. (2000).

Mature Hereford cows (766) were mated to 97 sires from seven breeds: Jersey, Wagyu, Angus, Hereford, South Devon, Limousin, and Belgian Blue. There were 1,215 male and female calves born over $4 \mathrm{yr}$ (1994 to 1997). Thus, on average there were 13.9 sires per breed and 12.5 calves per sire. Sires were generally, although not always, only used in $1 \mathrm{yr}$ whereas it was common for dams to be used for more than $1 \mathrm{yr}$. Cohort is identified by year of birth and sex. The complete data set comprises $59 \%$ more animals than previously reported by MalauAduli et al. (2000) due to the addition of 1996-born steers and 1997-born heifers and steers. Some additional traits are also reported.

The cattle in this project were raised in a typical "Mediterranean environment," characterized by cool, wet winters and hot, dry summers. Pasture growth generally occurs between April and November. Calves were born when there was minimal pasture availability (average birth date was April 3). They were tagged, measured (weight, height, length, girth), and castrated (bulls only) within $3 \mathrm{~d}$ of birth. Calves were born on two South Australian properties (Struan and nearby Wandilo) in three management groups. All calves were weaned in early January at an average age of 9 mo. After weaning, Wandilo calves were transported to Struan where they were mixed with Struan-born calves and randomly allocated to between one and three post-weaning management groups. Calves were grown until 12 to $18 \mathrm{mo}$ of age and then transported to a commercial feedlot. In the feedlot, they were fed a minimum of $60 \%$ grain (various, but primarily barley) with approximately $12 \mathrm{MJ} / \mathrm{kg} \mathrm{DM} \mathrm{ME}$ and 13\% protein for 70 to $90 \mathrm{~d}$ (heifers) or 150 to $180 \mathrm{~d}$ (steers). The exception to this was the 1997 steers that, after a good pasture season in 1998, reached marketable weights without requiring grain finishing.

Calves were slaughtered when the majority of heifer carcasses were $>200 \mathrm{~kg}$ (average $=16 \mathrm{mo}$ ) and steer carcasses $>300 \mathrm{~kg}$ (average $=23 \mathrm{mo}$ ) at various commercial abattoirs throughout southeastern Australia. They were assessed for hot standard carcass weight (HSCW) based on a standard trim (AUSMEAT, 1995), fat depth over the rump at the P8 position (P8) as described by Arthur et al. (2001), fat color (FCS) at the site of quartering (generally 10th to 11th rib), and various other traits not included in this paper. Fat color is scored as yellowness from 0 (bright white) to 9 (yellow-orange). Kruk et al. (1999) has quantified the amount of $\beta$-carotene, the primary yellow pigment in beef fat, in each fat color score as $0.48 \times \mathrm{FCS}+0.885(\mu \mathrm{g} / \mathrm{g})$. Fat and meat $(\mathrm{M}$. longissimus dorsi) samples were taken from the site of quartering for determination of i.m. fat content (IMF), melting point of the fat (MP), and fatty acid composition.

\section{Lipid Extraction, Fractionation, and Fatty Acid Composition}

The methods used for fatty acid analyses were similar to those recommended by Christie (1989). Total lipids were extracted from samples of s.c. fat (approximately $0.1 \mathrm{~g}$ ) or muscle (approx. 1 to $2 \mathrm{~g}$ ) with chloroform/methanol. The methyl esters of the first group of samples (1994 calves) were prepared by base-catalyzed procedures using sodium methoxide, whereas later samples were prepared by acid-catalyzed procedures using $1 \% \mathrm{H}_{2} \mathrm{SO}_{4}$ in dried methanol (Malau-Aduli et al., 1996).

\section{Fatty Acid Analysis}

Fatty acids were identified and quantified by gas-liquid chromatography using a Hewlett Packard gas chromatograph (model 5890, Avondale, PA) fitted with fusedsilica capillary columns (either BP20 or BPX70, SGE, Melbourne, Australia). Hydrogen was used as the carrier gas. Individual fatty acids were identified by comparison of retention times with known reference standards. The integrated values (percent of total) for each component were calculated as normalized values with respect to those identified. Total saturated (SFA) and cis-monounsaturated fatty acids (MUFA) were calculated by summing appropriate components. In addition, indices of desaturation (addition of a double bond) and elongation (conversion from 16 to 18 carbon atoms) were calculated as follows:

Total saturated fatty acids $=14: 0+16: 0+17: 0+18: 0$ Total cis-monounsaturated fatty acids $=14: 1+16: 1+$ $17: 1+18: 1(\mathrm{n}-9)+18: 1(\mathrm{n}-7)$

Desaturation index $=100[(18: 1 n-9) /(18: 0+18: 1 n-9)]$

Elongation index $=100[(18: 0+18: 1 n-9) /(16: 0+16: 1+$

$$
18: 0+18: 1 n-9)]
$$


Fatty acid composition of crossbred cattle

Table 1. Description of traits and heritability estimates

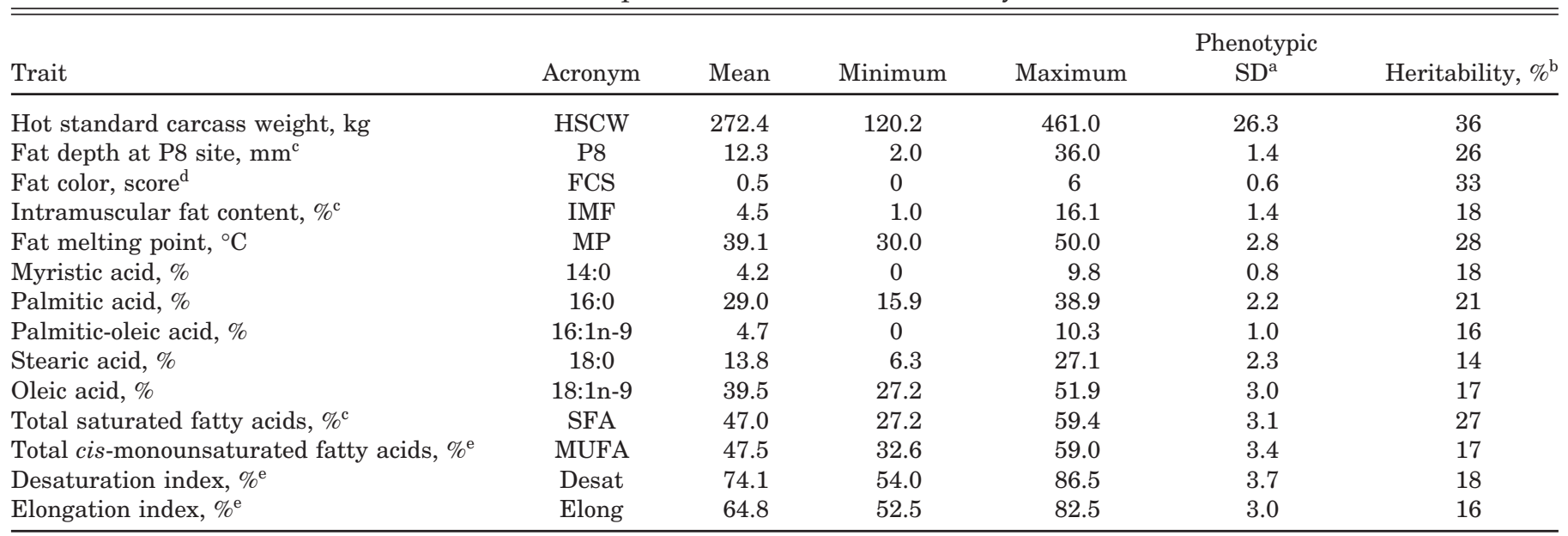

${ }^{a}$ Residual phenotypic standard deviation after model fitted.

${ }^{\text {b }}$ Standard errors of heritability estimates were 6 to $8 \%$.

${ }^{\mathrm{c}} \mathrm{Log}$ transformation used for analysis. Results are transformed back to the original scale.

${ }^{\mathrm{d}}$ Fat color scores from bright white (0) to yellow-orange (9).

e'See text for descriptions of calculated values.

\section{Melting Point Determination}

Melting point was recorded as the "slip point" determined according to AOCS (1993), except that instead of using a water bath, the samples were placed in the wells (filled with water) of a DNA thermocycler (Perkin Elmer Cetus Australia Ltd.). The thermocycler temperature was raised by $1^{\circ} \mathrm{C} / \mathrm{min}$ from 25 to $50^{\circ} \mathrm{C}$ after a 5 min equilibration period at $25^{\circ} \mathrm{C}$. The capillary tubes were checked at each degree centigrade rise in temperature and then returned to the well. The temperature at which the fat "slipped" was recorded as the melting point.

\section{Statistical Analyses}

Data were analyzed using ASREML (Gilmour et al., 2000). All traits (Table 1) were analyzed with a univariate animal model containing fixed effects of cohort (eight combinations of year of birth and sex), management group (total of 30 levels describing pre- and postweaning groups, 2 to 6 per cohort), birth month (March or April), and sire breed (seven levels). Birth month was used to test age effects rather than a linear covariate of birth day to avoid bias (high leverage) resulting from small numbers of very early or very late calves. Factors with more levels were tested but birth month seemed the most appropriate.

Two-way interactions were generally not significant and were not included. A log transformation was used for IMF and P8 fat depth because of heterogeneous variance. Least squares means for IMF and P8 fat were back transformed by ASREML (chapter 6.1.1). The significance of sire breed was effectively tested against sire as outlined by Gilmour et al. (2000). Bivariate animal models with the same fixed effects were used for estimation of phenotypic, genetic and environmental correlations.

\section{Results}

\section{Environmental Effects}

Cohort differences (Table 2) were largely due to yearly and seasonal variations in pasture availability (e.g., 1995 calves were $50 \mathrm{~kg}$ heavier at weaning than the 1994 calves; data not reported), age of entry into feedlot, and time on feed. Management group effects were generally of low magnitude or nonsignificant, and are not reported. Across cohorts (Table 2), carcass weight and fat depth were closely related. The notable exception was the 1997 steers, which were the only group not to be feedlot-finished.

Another large cohort effect was on fat color as all the feedlot-finished carcasses were much whiter (average 0.2 resulting from mostly zero scores) than the pasturefinished 1997 steers $(3.0 \pm 0.1)$. The 1996 steers had the highest intramuscular fat $(6.9 \pm 0.3 \%)$, and the 1995 and 1996 heifers had the lowest. Cohort differences were also highly significant for fatty acid composition. The only pasture-finished group (1997 steers) had the lowest desaturation index, one of the lowest melting points, and one of the highest elongation indices. The 1994 calves (heifers and steers) had the highest level of MUFA.

Differences between early- (March) and late- (April) born calves (Table 2) were small for carcass weight $(3 \mathrm{~kg})$ and no differences in fatness or fat color were observed. However, there were highly significant differences in fatty acid composition, as March born calves had fat with $0.5^{\circ} \mathrm{C}$ lower melting point, $0.6 \%$ higher MUFA, and $0.7 \%$ higher desaturation index.

\section{Genetic Effects}

Sire breed effects were important (Table 2) for all traits except the fatty acid elongation index. There were 
Table 2. Least squares means for cohort and sire breed

\begin{tabular}{|c|c|c|c|c|c|c|c|c|}
\hline Item & $\begin{array}{c}\mathrm{HSCW}^{\mathrm{a}} \\
(\mathrm{kg})\end{array}$ & $\begin{array}{c}\text { P8 } \\
(\mathrm{mm})\end{array}$ & $\begin{array}{l}\text { FCS } \\
\text { (score) }\end{array}$ & $\begin{array}{l}\mathrm{IMF} \\
(\%)\end{array}$ & $\begin{array}{l}\mathrm{MP} \\
\left({ }^{\circ} \mathrm{C}\right)\end{array}$ & $\begin{array}{c}\text { MUFA } \\
(\%)\end{array}$ & $\begin{array}{c}\text { Desat } \\
(\%)\end{array}$ & $\begin{array}{c}\text { Elong } \\
(\%)\end{array}$ \\
\hline Cohort & $* * *$ & $* * *$ & $* * *$ & $* * *$ & $* * *$ & $*$ & $* * *$ & $* * *$ \\
\hline 1995 Heifers & 202 & 8.3 & 0.0 & 2.5 & 38.2 & 47.8 & 76.3 & 63.5 \\
\hline 1996 Heifers & 213 & 9.6 & 0.2 & 2.8 & 40.0 & 47.5 & 74.0 & 64.7 \\
\hline 1997 Heifers & 202 & 8.6 & 0.3 & 4.7 & 38.7 & 46.3 & 73.0 & 65.8 \\
\hline 1996 Steers & 361 & 14.7 & 0.0 & 6.9 & 39.2 & 44.3 & 72.5 & 64.8 \\
\hline 1997 Steers & 271 & 8.9 & 3.0 & 4.5 & 38.5 & 45.8 & 71.2 & 67.0 \\
\hline SE range & 4 to 6 & 0.5 to 0.7 & 0.1 & 0.1 to 0.3 & 0.4 to 0.7 & 0.5 to 0.8 & 0.5 to 0.9 & 0.4 to 0.7 \\
\hline Birth month & $*$ & & & & $* * *$ & $* * *$ & $* * *$ & \\
\hline March & 270 & 10.9 & 0.6 & 3.9 & 38.9 & 47.8 & 74.3 & 65.2 \\
\hline April & 267 & 10.7 & 0.6 & 3.9 & 39.4 & 47.2 & 73.6 & 65.0 \\
\hline Angus & $283^{\mathrm{w}}$ & $14.3^{\mathrm{w}}$ & $0.5^{\mathrm{x}}$ & $4.6^{\mathrm{w}}$ & $39.4^{\mathrm{w}}$ & $47.4^{\mathrm{x}}$ & $74.2^{\mathrm{x}}$ & $65.0^{\mathrm{wx}}$ \\
\hline Hereford & $268^{x}$ & $12.0^{\mathrm{x}}$ & $0.4^{\mathrm{x}}$ & $3.7^{\mathrm{x}}$ & $40.0^{\mathrm{w}}$ & $46.6^{\mathrm{x}}$ & $72.4^{\mathrm{y}}$ & $65.4^{\mathrm{wx}}$ \\
\hline South Devon & $284^{\mathrm{w}}$ & $9.8^{\mathrm{y}}$ & $0.5^{\mathrm{x}}$ & $3.8^{\mathrm{x}}$ & $40.3^{\mathrm{w}}$ & $46.7^{x}$ & $72.5^{\mathrm{y}}$ & $65.2^{\mathrm{wx}}$ \\
\hline Limousin & $278^{\mathrm{w}}$ & $9.9^{y}$ & $0.4^{\mathrm{x}}$ & $3.1^{\mathrm{y}}$ & $40.2^{\mathrm{w}}$ & $47.0^{\mathrm{x}}$ & $73.4^{\mathrm{xy}}$ & $65.0^{\mathrm{wx}}$ \\
\hline Belgian Blue & $289^{\mathrm{w}}$ & $8.0^{\mathrm{z}}$ & $0.6^{x}$ & $3.0^{\mathrm{y}}$ & $39.3^{\mathrm{w}}$ & $47.1^{\mathrm{x}}$ & $73.7^{\mathrm{x}}$ & $65.0^{\mathrm{wx}}$ \\
\hline SE range & 3 to 4 & 0.3 to 0.6 & 0.1 & 0.1 to 0.2 & 0.3 to 0.4 & 0.3 to 0.4 & 0.4 to 0.5 & 0.3 to 0.4 \\
\hline
\end{tabular}

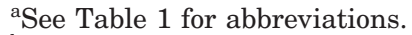

${ }^{\mathrm{b}}$ Sire breed means with different superscripts were significantly different.

$* P<0.05, * * P<0.01,{ }^{*} * * P<0.001$.

four breeds (Angus, South Devon, Limousin, and Belgian Blue) that were, on average, $6 \%$ heavier than the purebred Hereford. The Wagyu (9\%) and Jersey (12\%) were lighter than the Hereford. The Angus had by far the highest s.c. fat depth (19\% more than Hereford and Wagyu), with Jersey being $11 \%$ lower than Hereford, followed by South Devon and Limousin (18\% lower) and Belgian Blue (33\% lower). The only difference in fat color was that Jersey crosses scored more yellow than the other breeds. Jersey, Wagyu, and Angus had 25\% more intramuscular fat than Hereford and South Devon (4.6 vs 3.8\%) with Limousin and Belgian Blue being the lowest (18\% less than Hereford).

The Jersey and Wagyu (higher marbling breeds) had softer fat (6\% lower melting point) than the other breeds (Table 2). They also had higher levels of MUFA and a higher index of desaturation but not elongation. The Angus was more highly marbled like the Jersey and Wagyu but had harder fat, similar to that of the leaner breeds.

Heritability was calculated after adjustment for environmental (cohort, management group, birth month) fixed effects and sire breed (Table 1). Carcass weight and fat color were the most highly heritable traits (36 and $33 \%$ respectively). The average heritability of specific fatty acids was $17 \%$, but was higher for melting point (28\%). Most traits were moderate to low, although still significantly, heritable.

While the genetic correlations calculated from 1,215 calves from 97 sires had high standard errors (average
0.2 ), they still yielded interesting results (Table 3). For instance, the genetic correlation between SFA and MUFA was $-0.95 \pm 0.05$. This was not surprising since PUFA (the only other class) were very low such that SFA and MUFA virtually sum to $100 \%$ and are negatively correlated by definition.

Correlations between fat traits and carcass weight were weak, the greatest being fat melting point (0.34). Melting point was genetically correlated with level of MUFA (-0.42) and desaturation index $(-0.46)$, but not the elongation index $(-0.05)$. As expected, and almost by definition, the level of MUFA was highly correlated with the indices of desaturation (0.87) and elongation (0.69). Intramuscular fat content was possibly genetically correlated with the elongation index $(-0.61)$. These genetic correlations were often larger (although nonsignificant) than the phenotypic correlations because the environmental and genetic correlations were opposite in direction.

Genetic correlations between specific fatty acids and carcass weight, fat depth, intramuscular fat, and fat color were generally weak $(-0.25$ to 0.28 ; data not shown). Two possible exceptions were IMF with palmitic acid $(0.43 \pm 0.28)$ and oleic acid $(-0.48 \pm 0.31)$. However, some genetic correlations between specific fatty acids and melting point and calculated fat traits (MUFA, desaturation index, and elongation index) were strong. Genetic variation in melting point (Table 4) was most closely associated with variation in palmitoleic acid (16:1, -0.74) and stearic acid (18:0, 0.54). Not sur- 
Fatty acid composition of crossbred cattle

Table 3. Phenotypic (above diagonal) and genetic (below diagonal) correlations

between selected traits

\begin{tabular}{|c|c|c|c|c|c|c|c|c|}
\hline & $\mathrm{HSCW}^{\mathrm{a}}$ & P8 & FCS & IMF & MP & MUFA & Desat & Elong \\
\hline HSCW & & 0.31 & 0.00 & 0.08 & -0.09 & 0.04 & 0.09 & 0.02 \\
\hline P8 & 0.22 & & -0.02 & 0.15 & -0.13 & 0.12 & 0.16 & 0.01 \\
\hline FCS & -0.04 & -0.14 & & 0.03 & -0.13 & 0.10 & 0.12 & 0.04 \\
\hline IMF & 0.00 & 0.36 & 0.00 & & -0.10 & 0.08 & 0.12 & -0.04 \\
\hline MP & 0.34 & 0.20 & 0.16 & 0.06 & & -0.50 & -0.54 & -0.11 \\
\hline MUFA & -0.10 & 0.07 & 0.11 & -0.27 & -0.42 & & 0.76 & 0.54 \\
\hline Desat & -0.07 & 0.06 & -0.05 & 0.04 & -0.46 & 0.87 & & -0.04 \\
\hline Elong & 0.24 & -0.17 & -0.21 & -0.61 & -0.05 & 0.69 & 0.33 & \\
\hline
\end{tabular}

a See Table 1 for abbreviations. Standard errors of phenotypic correlations $=0.01$ to 0.03 and genetic correlations $=0.09$ to 0.32 .

prisingly, the calculated variables were highly genetically correlated to specific fatty acids: MUFA and oleic acid (0.90), desaturation index and stearic acid (-0.94), and elongation index and palmitic acid (-0.95). There were also some high genetic correlations between specific fatty acids: $14: 0$ and 16:0 (0.62 \pm 0.15$), 14: 0$ and $18: 1 \mathrm{n}-9(-0.87 \pm 0.12), 16: 0$ and $18: 1 \mathrm{n}-9(-0.79 \pm 0.13)$, and $16: 1$ and 18:0 $(-0.60 \pm 0.18)$.

\section{Discussion}

\section{Fat Color}

In each of the $4 \mathrm{yr}$ of the Project, postweaning management was different for heifers and steers. The heaviest and fattest heifers were those born in 1994 (Table 2 ). They were also the oldest group of heifers when starting in the feedlot so the effect is primarily due to age at entry. The lightest steers were those born in 1997. At the end of their second spring ( 21 mo of age in December 1998), they were sufficiently heavy and fat to slaughter, thus feedlot finishing would have been unprofitable. Since these steers were slaughtered straight off pasture, they also had by far the most yellow fat.

The fact that the 1997 steers were the same fatness as some of the 70-d grain-fed heifers but had more yellow fat (higher score) provides evidence that during feedlot finishing with grain-based diets, $\beta$-carotene (the yellow pigment) in the fat is reduced quite quickly. The study by Strachen et al. (1993) supports this observation by reporting that with Australian Bos indicus steers, fat color score was reduced from 3.9 to 2.4 after only $35 \mathrm{~d}$ of grain feeding. Because most cohorts only gained $1 \mathrm{~mm}$ P8 fat per month (not reported), but presumably entered the feedlot with fat color scores equivalent to the 1997 steers, it appeared that $\beta$-carotene was being removed from the fat in addition to simply being diluted by fattening.

To demonstrate the "dilution hypothesis." it is possible to use two relationships: 1 ) between $\beta$-carotene concentration and fat color score $(\beta$-carotene $=0.48 \times$ FCS +0.885 ; Kruk et al., 1999); and 2) a relationship between $\beta$-carotene concentration and P8 fat depth for the four steer cohorts $\left(\beta\right.$-carotene $=8.8+\ln \mathrm{P}^{-3}, \mathrm{R}^{2}=$ 0.995; Table 2). Based on these, for fat color score to be reduced from 3.0 to 0.5 (83\% drop), total $\beta$-carotene could remain the same but concentration would fall from 2.325 to $1.125 \mu \mathrm{g} / \mathrm{g}$ (52\% drop). This dilution (reduction in concentration) would be associated with P8 fat depth increasing from 8.7 to $12.9 \mathrm{~mm}$ (48\%, assuming all had same amount of $\beta$-carotene at feedlot entry), which could occur in approximately $126 \mathrm{~d}$. Thus, as practiced by industry, diluting previously accumulated $\beta$-carotene during grain feeding can result in a large improvement in fat color score in a short period of time (often around $70 \mathrm{~d}$ ).

Heritability estimates using the complete data set were all higher and had lower standard errors than

Table 4. Phenotypic and genetic correlations between selected traits and specific fatty acids

\begin{tabular}{|c|c|c|c|c|c|c|c|c|}
\hline & \multicolumn{4}{|c|}{ Phenotypic } & \multicolumn{4}{|c|}{ Genetic } \\
\hline & $\mathrm{MP}^{\mathrm{a}}$ & MUFA & Desat & Elong & MP & MUFA & Desat & Elong \\
\hline $14: 0$ & 0.06 & -0.34 & 0.02 & -0.75 & -0.06 & -0.61 & -0.27 & -0.79 \\
\hline $16: 0$ & 0.20 & -0.48 & -0.06 & -0.91 & 0.25 & -0.75 & -0.32 & -0.95 \\
\hline $16: 1 n-9$ & -0.36 & 0.30 & 0.56 & -0.35 & -0.74 & 0.39 & 0.55 & -0.30 \\
\hline $18: 0$ & 0.47 & -0.39 & -0.86 & 0.33 & 0.54 & -0.66 & -0.94 & 0.18 \\
\hline $18: 1 n-9$ & -0.36 & 0.81 & 0.40 & 0.70 & -0.09 & 0.90 & 0.66 & 0.87 \\
\hline
\end{tabular}

asee Table 1 for abbreviations. Standard errors of phenotypic correlations $=0.004$ to 0.03 and genetic correlations $=0.02$ to 0.24 . 
preliminary estimates (Malau-Aduli et al., 2000). Koots et al. (1994a) reviewed heritability estimates in beef cattle. They found that for most traits, there were large breed differences in the estimates, and they concluded that these were likely to be a function of both small data sets as well as real differences. Compared to Koots et al., the heritability estimate for carcass weight was higher (36 vs $23 \%$ ) and fat depth was lower (26 vs $44 \%$ ). The heritability estimate for fat color was $33 \%$ (Table 1). However, most of the genetic variation reported came from the Jersey cross calves (Kruk, 2001), and when these were removed from the data set, then the heritability was much lower (16\%), resulting from a $58 \%$ reduction in the genetic variance. Thus, for six of the breeds tested, variation in fat color was primarily environmental.

\section{Fat Distribution}

Subcutaneous fat depth and IMF are important determinants of carcass and meat quality. In addition to some market requirements for marbling, an even covering of fat is important to prevent rapid cooling of the carcass resulting in cold shortening and tough meat (Lawrie, 1998). To minimize wastage and maximize meat quality, it would seem to be desirable to increase marbling relative to $\mathrm{P} 8$ fat depth. In this study, there were large differences between cohorts in marbling and fat depth. The 1995 and 1996 heifers had the lowest intramuscular fat, probably because they were slaughtered so young (around 15 mo). However, 1997 heifers were also young and had similar P8 fat depth, but more intramuscular fat than the 1995 and 1996 heifers (4.7 vs 2.5 to $2.8 \%$ ). While these results indicate a large potential for management of calves to increase i.m. fat relative to s.c. fatness, it is not clear what caused these differences. There were also differences between steer cohorts that were probably due to a combination of differences in age, time on feed, condition at feedlot entry, and the specific feedlot diet.

Breed differences in fat depth and IMF in both absolute and relative measures were large. For IMF, there were three fat (Angus, Wagyu, and Jersey), two intermediate (Hereford and South Devon), and two lean (Limousin and Belgian Blue) breed crosses (Table 2). However, breed rankings for fat depth were different. If breed cross means for IMF are plotted against fat depth, three of the breed crosses were close (average) to the trend-line (Angus, South Devon and Belgian Blue). Of the other crosses, two had more marbling (desirable) than expected (Jersey and Wagyu), and two had less marbling (undesirable) than expected (Hereford and Limousin). The breed rankings are very similar to those found by the USDA Germ Plasm Evaluation program (e.g., Gregory et al., 1994, Wheeler et al., 2001). Both studies demonstrate large differences, such as the high yields of lean meat from the Limousin and Belgian Blue, and smaller but consistent differences, such as the Angus being fatter (s.c. and i.m.) than Hereford. However, both studies suggest there is opportunity to select breed combinations that enable IMF to be maximized relative to s.c. fat.

Koots et al. (1994a) reported heritability of marbling score as $38 \%$, a value significantly higher than the heritability of i.m. fat content (18\%), reported herein (Table 1 ). While it could be argued that marbling score vs chemical extraction caused the difference, usually a score would be considered less accurate and, hence, less heritable. In the current trial, when the leaner breeds (South Devon, Limousin, and Belgian Blue) were excluded from the analysis, the heritability for marbling was much higher (not reported). Others, such as Oikawa et al. (2000), have reported high heritability estimates for marbling in highly marbled breeds (Wagyu). These differences highlight the importance of treating the current estimates as "pooled" across breeds rather than specific to any one breed. The estimates by Koots et al. (1994a) were also pooled across studies, but probably included a lower proportion of data from low-marbling breeds than in this study.

Correlations between production traits (weight and fatness) were low. The strongest phenotypic correlation was between carcass weight and fat depth $(0.31$; Table 3 ), but the genetic correlation of 0.22 was not significant. Carcass weight and IMF were uncorrelated (0.00), even lower than that reported by Koots et al. (1994b) for carcass weight and marbling score (0.15). The strongest genetic correlation for production traits was between the two measures of fatness: s.c. fat depth (P8) and IMF (0.36), which is higher than that reported in U.S. (Gregory et al., 1994), Japanese (Oikawa et al., 2000), and other Australian cattle (Reverter et al., 2000). The low correlation between these two measures of fatness indicates ample potential to select animals within breeds for improvements in both s.c. (not desirable) and i.m. (highly desirable) fat.

\section{Fatty Acid Composition}

In addition to market requirements for fat cover and marbling, softer fat is more quickly and safely processed by boning room workers, as well as potentially having some flavor advantages (May et al., 1993). The melting point (hardness) of long-chain fatty acids and their esters is related to the proportion of unsaturated fatty acids present (Litchfield, 1972). Melting point decreases as the proportion of unsaturated fatty acids increases (Gurr and Harwood, 1991). Cohort differences were also highly significant for fatty acid composition and melting point. While the only pasture-finished group (1997 steers) had the lowest desaturation index, low melting point, and high elongation index, trends across cohorts were not consistent for the traits reported. An example of this inconsistency is that high MUFA was expected to be associated with low melting point. This relationship was stronger from the phenotypic correlation $(-0.50$; Table 3$)$ than across cohort means $(r=0.27)$. An indication of the importance of diet is that the 1994 
steers and heifers were the only two cohorts that were in the feedlot together (although for different times), and both had high MUFA with average fat melting points.

Birth month (age) of calves had no effect on fatness (P8 or IMF; Table 2), and only a small effect on weight (approximately $0.1 \mathrm{~kg} / \mathrm{d}$ ). However, there was a significant effect on fatty acid composition where older (March) calves had lower levels of saturated fat causing softer fat (Table 2). It is likely that the age effect is due to greater desaturation via the stearoyl-CoA-desaturase enzyme, as also indicated by the difference in desaturation indices ( 74.3 vs $73.6 \%$; Table 2 ).

The age effect on enzyme activity supports the hypothesis that early-maturing breeds have lower levels of saturated fats (e.g., Johnson, 1987). Johnson demonstrated that large, lean breeds (e.g., Charolais) have lower levels of MUFA than smaller, early maturing breeds (e.g., Angus or Hereford). Other studies with Hereford crosses in Australia (Siebert et al., 1996) and Brahman crosses in the United States (Huerta-Leidenz et al., 1993) also confirmed this observation. Herein (Table 2), the Wagyu and Jersey had the most marbling (i.m. fat) and had soft fat (highly monounsaturated). The Wagyu results are consistent with previous studies (e.g., May et al., 1993; Yang et al., 1999). The Jersey was similar to Wagyu but its fat was more yellow. However, Angus-cross calves had the most s.c. fat (indicator of early maturity), but were certainly not the smallest, and had fat composition similar to the very lean Limousin and Belgian Blue. Also, the different slaughter ages of cohorts in this study did not add support for the general physiological age effects. This may not be surprising because of the large number of other differences between cohorts discussed above.

Across breeds, there appeared to be no relationship between fat depth and melting point or MUFA. Also, within breeds, the genetic correlations (Table 3) between fat depth and melting point or MUFA were very low ( 0.20 and 0.07 respectively), as it was with most other fatty acid composition traits. Melting point was genetically correlated with MUFA (-0.42) and desaturation index $(-0.46)$, but not elongation $(-0.05)$. In contrast to the trend across breeds, elongation was correlated with intramuscular fat $(-0.61$; Table 3$)$.

There was some indication that for fatty acid related traits; the phenotypic correlations with production traits (e.g., carcass weight, fatness, and fat color) may be different from the genetic correlations. An example of this is HSCW and fat melting point, where the phenotypic, genetic, and environmental correlations were $-0.09,0.34$, and -0.28 , respectively. While correlations with fat color were low, if the true genetic and environmental correlations were opposite in direction, then conflicting conclusions (e.g., Zhou et al., 1993, MalauAduli et al., 1997) about the relationship between fat color and fatty acid composition between and within previous trials would be expected.
Yang et al. (1999) used the ratio of oleic acid (18:1n9) to palmitic acid (16:0) as a useful indicator of fatty acid composition. The conversion of palmitic to oleic acid occurs due to two enzymes: $\Delta^{9}$-desaturase and elongase. In the current study, the genetic correlation between these two fatty acids was very high $(-0.79 \pm 0.13)$. This supports the close interconnection between the two fatty acids, but also suggests that a ratio between them would add little information above simply knowing their individual levels since the high correlation indicates they are almost the same trait. The indices used herein are designed to more closely reflect the underlying biochemistry. However, while they are useful indicators, the additional understanding gained was smaller than expected because they were also highly correlated to individual fatty acids (Table 4).

\section{Implications}

Carcass weight and fatness are important determinants of carcass value. In addition to market requirements for fat cover and marbling, softer fat is superior for abattoir processing and flavor, and in the future there may be demand for beef with specific fatty acid profiles. There were large differences in these traits both between cohorts and the seven crossbreeds. In addition, these traits were moderately heritable. Thus, combining management, breed utilization, and selection could lead to large improvement in production of quality beef. Furthermore, there was no strong evidence of antagonisms between traits that would prevent progress.

\section{Literature Cited}

AOCS. 1993. Official Methods. pp 3-25. American Oil Chemists Society, Champaign, IL.

Arthur, P. F., J. A. Archer, D. J. Johnson, R. M. Herd, E. C. Richardson, and P. F. Parnell. 2001. Genetic and phenotypic variance and covariance components for feed intake, feed efficiency, and other postweaning traits in Angus cattle. J. Anim. Sci. 79:2805-2811.

AUSMEAT. 1995. Handbook of Australian Meat. 5th ed. Australian Meat and Livestock Corporation, Brisbane, Australia.

Baud, S., C. M. Wade, and M. E. Goddard. 1998. Relationships among carcass quality characteristics between and within carcass quartering sites. Aust. J. Agric. Res. 49:285-291.

Bout, J., J. P. Girard, P. Sellier, and J. P. Runavot. 1991. Genetic parameters of compositional traits of backfat and longissimus dorsi muscle in pigs. Anim. Breed. Abstr. 59:162.

Cameron, N. D., and M. B. Enser. 1991. Fatty acid composition in lipid in longissimus dorsi muscle of Duroc and British Landrace pigs and its relationship with eating quality. Meat Sci. 29:295-307.

Christie, W. W. 1989. Gas Chromatography and Lipids: a Practical Guide. The Oily Press, Ayr, Scotland.

Gilmour, A. R., R. Thompson, B. R. Cullis, and S. J. Welham. 2000. ASREML. User Notes. New South Wales Agriculture, Orange, NSW, Australia.

Gregory, K. E., L. V. Cundiff, R. M. Koch, M. E. Dikeman, and M. Koohmaraie. 1994. Breed effects, retained heterosis, and estimates of genetic and phenotypic parameters for carcass and meat traits of beef cattle. J. Anim. Sci. 72:1174-1183. 
Gurr, M. I., and J. L. Harwood. 1991. Lipid Biochemistry: An Introduction. Chapman and Hall, London, UK.

Huerta-Leidenz, N. O., H. R. Cross, J. W. Savell, D. K. Lunt, J. F. Baker, L. S. Pelton, and S. B. Smith. 1993. Comparison of the fatty acid composition of subcutaneous adipose tissue from mature Brahman and Hereford cows. J. Anim. Sci. 71:625-630.

Johnson, E. R. 1987. Marbling fat in beef. Meat Sci. 20:267-279.

Koots, K. R., J. P. Gibson, C. Smith, and J. W. Wilton. 1994a. Analyses of published genetic parameter estimates for beef production traits. 1. Heritability. Anim. Breed. Abstr. 62:309-338.

Koots, K. R., J. P. Gibson, and J. W. Wilton. 1994b. Analyses of published genetic parameter estimates for beef production traits. 2. Phenotypic and genetic correlations. Anim. Breed. Abstr. 62:825-844.

Kruk, Z. A. 2001. Genetic and non-genetic factors affecting carotenoid concentration in cattle tissues. $\mathrm{PhD}$. Dissertation, The University of Adelaide, Australia.

Kruk, Z. A., W. S. Pitchford, and C. D. K. Bottema. 1999. Relationship between cattle fat color at weaning and slaughter. Pages 450451 in Proc. 45th Int. Cong. of Meat Sci. and Technol. Yokohama, Japan.

Lawrie, R. A. 1998. Lawrie's Meat Science. Woodhead Publishing, Cambridge.

Litchfield, C. 1972. Analysis of Triglycerides. Academic Press, New York.

Malau-Aduli, A. E. O., M. A. Edriss, B. D. Siebert, C. D. K. Bottema, and W. S. Pitchford. 2000. Breed differences and genetic parameters for melting point, marbling score and fatty acid composition of lot-fed cattle. J. Anim. Physiol. Anim. Nutr. 83:95-105.

Malau-Aduli, A. E. O., B. D. Siebert, C. D. K. Bottema, and W. S. Pitchford. 1996. Genetic comparison of the fatty acid composition of intramuscular and adipose tissue from early and late maturing beef cattle. In: Proc. 8th Cong. Asian Australasian Assoc. Anim. Prod. Soc., Tokyo, Japan.

Malau-Aduli, A. E. O., B. D. Siebert, C. D. K. Bottema, and W. S. Pitchford. 1997. A comparison of the fatty acid composition of triacylglycerols in adipose tissue from Limousin and Jersey cattle. Aust. J. Agric. Res. 48:715-722.
Malau-Aduli, A. E. O., B. D. Siebert, M. P. B. Deland, C. D. K. Bottema, and W. S. Pitchford. 1998. Heritabilities of triacylglycerol fatty acids from the adipose tissue of beef cattle at weaning and slaughter. Proc. 6th World. Cong. Genet. Appl. Livest. Prod., Armidale, NSW, Australia. 25:181-184.

May, S. G., C. A. Sturdivant, D. K. Lunt, R. K. Miller, and S. B. Smith. 1993. Comparison of sensory characteristics and fatty acid composition between Wagyu crossbred and Angus steers. Meat Sci. 35:289-298

Oikawa, T., T. Sanehira, K. Sato, Y. Mizoguchi, H. Yamamoto, and M. Baba. 2000 Genetic parameters for growth and carcass traits of Japanese Black (Wagyu) cattle. Anim. Sci. 71:59-64.

Perry, D., P. J. Nicholls, and J. M. Thompson. 1998. The effect of sire breed on the melting point and fatty acid composition of subcutaneous fat in steers. J. Anim. Sci. 76:87-95.

Reverter, A., D. J. Johnston, H.-U. Graser, M. L. Wolcott, and W. H. Upton. 2000. Genetic analysis of live-animal ultrasound and abattoir carcass traits in Australian Angus and Hereford cattle. J. Anim. Sci. 78:1786-1795.

Rutley, D. L., M. P. B. Deland, and W. S. Pitchford. 1995. Crossbreeding beef cattle in Southern Australia. Proc. Aust. Assoc. Anim. Breed. Gen., Roseworthy, Australia. 11:151-154.

Siebert, B. D., M. P. B. Deland, and W. S. Pitchford. 1996. Breed differences in the fatty acid composition of subcutaneous and intramuscular lipid of early and late maturing, grain-finished cattle. Aust. J. Agric. Res. 47:943-952.

Strachen, D. B., A. Yang, and R. D. Dillon. 1993. Effect of grain feeding on fat color and other carcass characteristics in previously grassfed Bos indicus steers. Aust. J. Exp. Agric. 33:269-273.

Wheeler, T. L., L. V. Cundiff, S. D. Shackleford, and M. Koohmaraie. 2001. Characterization of biological types of cattle (Cycle V): Carcass traits and longissimus palatability. J. Anim. Sci. 79:1209-1222.

Yang, A., T. W. Larsen, V. H. Powell, and R. K. Tume. 1999. A comparison of fat composition of Japanese and long-term grainfed Australian steers. Meat Sci. 51:1-9.

Zhou, G. H., A. Yang, and R. K. Tume. 1993. A relationship between bovine fat color and fatty acid composition. Meat Sci. 35:205. 